Disclosure of Interests: Wendy Gerhart Grant/research support from: The Canadian Spondylitis Association received funding from multiple pharmaceutical companies for the comorbidity awareness campaign., Employee of: I was employed by Janssen Canada until October 2016. I have been working with the Canadian Spondylitis Association since March 1, 2017. Janssen did not provide support for the awareness campaign., Gerald Major: None declared, Austin Gerhart: None declared, Marilyn Walsh: None declared

DOI: 10.1136/annrheumdis-2019-eular.7046

\section{OP0219-PARE LUPUS EUROPE YOUTH PANEL - WHAT WE LEARNED FROM YOUNG PEOPLE LIVING WITH LUPUS}

Alain Cornet ${ }^{1,2}$, Jeanette Andersen ${ }^{1} .^{1}$ Lupus Europe, Romford, essex, United Kingdom; ${ }^{2}$ CLAIR, St Maur, Belgium

Background: Since 2014, Lupus Europe conducts patient panels, where 10 to 12 persons from all over Europe living with lupus discuss the selected topic guided by facilitators living with lupus themselves. This allows to capture qualitative feedback of relevance, without the obstacle of the "white blouse". In 2018, 10 Young (18-27) European Lupus patients (8 female, 2 male) with diverse Lupus types met to discuss "Lupus and youth".

Objectives: Understand specificity of being young with lupus to better include young patients in Lupus groups action plans

Methods: 11 young patients, mostly with little or no involvement in patient groups were recruited through Lupus Europe's network. They were asked to send ahead of time their top challenges/issues living with lupus as well as their key questions for the panel. this input was used to build the 2 days program itself. Mid May, 10 of the 11 met face-to-face in Brussels, and explored multiple aspects of their input though 7 specifically designed interactive workshops

Results: While they considered taking pills every day as a key problem, they preferred to focus on the collective issues of being understood by friends and family and having to live with limitations.

A big "Wow" was the feeling of guilt expressed by several female participants (guilt of imposing limits to their partners, guilt of not being able to do as much as others

), a very important underlying dimension of their social and affective life, which is likely much misunderstood by doctors and patient organizations;

young people with lupus remain fundamentally more positive on their life with lupus than the average patients. While they perceive lupus as being "all over their lives", they refuse to be ruled by it

They view the future of a LUPUS EUROPE youth group as a "virtual group" on social media, with minimal commitment required, but bringing together "friends" around highly visual messages, short stories and the exchange of ideas that could lead to small group gatherings.

On the medical front, when we probed what would drive them to consider joining a clinical trial, clear first media is their lupus doctor, second are national lupus groups and LUPUS EUROPE. Other medias have a very limited impact.

Conclusion: Young patients needs must be addressed in a more aspirational way and using more virtual tools than average patients (more focused on health issues and geographic proximity).

The feeling of guilt of young women with regards to their affective life must be further explored to give them confidence and reassurance.

\section{REFERENCE:}

[1] Lupus Europe Patient panel 3 project report, acvailable on request at secretariat@lupus-europe.org

Disclosure of Interests: Alain Cornet Grant/research support from: No direct financial grants from Pharmaceutical companies, but some grants accrued LUPUS EUROPE does, in the form of Grants or payment for attending advisory boards or providing patient views, Speakers bureau: I have been involved in GSK panels to provide patient perspective. However, the minor service fee obtained accrued to LUPUS EUROPE ratyher than the company, Jeanette Andersen: None declared

DOI: 10.1136/annrheumdis-2019-eular.1212
THURSDAY, 13 JUNE 2019

\section{Fighting and fixing: from initiation to resolution of inflammation}

\section{OP0220 \\ SINGLE-CELL TRANSCRIPTOMIC AND FUNCTIONAL ANALYSES REVEAL NOVEL HETEROGENEITY IN PATHOGENIC PATHWAYS MEDIATED BY HUMAN SYNOVIAL TISSUE MACROPHAGES}

Samuel Finlay ${ }^{1,2}$, Lucy MacDonald ${ }^{1,2 *}$, Barbara Tolusso ${ }^{3}$, Aziza Elmesmari ${ }^{1,2}$, Maria Rita Gigante ${ }^{4}$, Clara DI Mario ${ }^{3}$, Luca Petricca ${ }^{3}$, Andrew Filer ${ }^{2,5}$, Neal L Millar ${ }^{1}$, Elisa Gremese ${ }^{3,4}$, lain Mcinnes ${ }^{1,2}$, Thomas Otto ${ }^{1,2}$, Stefano Alivernini ${ }^{3,4}$, Mariola Kurowska-Stolarska ${ }^{1,2}$. 'University of Glasgow, Institute of Infection Immunity and Inflammation, Glasgow, United Kingdom; ${ }^{2}$ Rheumatoid Arthritis Pathogenesis Centre of Excellence (RACE), Glasgow, Birmingham, Newcastle, United Kingdom; ${ }^{3}$ Fondazione Policlinico Universitario A. Gemelli IRCCS, Division of Rheumatology, Rome, Italy; ${ }^{4}$ Università Cattolica del Sacro Cuore, Rome, Italy, ${ }^{5}$ University of Birmingham, Institute of Infection, Inflammation and Ageing, Birmingham, United Kingdom

Background: We hypothesise that synovial tissue macrophages (STM) are heterogeneous and mediate discrete pathogenic pathways that may underlie partial or absent therapeutic responses in RA patients. Better understanding of STMs will provide novel targets for re-instating synovial homeostasis. We have shown that the human synovium contains at least two major populations of STMs (CD206/MerTK ${ }^{\text {neg }}$ and CD206/MerTK ${ }^{\text {pos }}$ ) with transcriptomes suggesting different function.

Objectives: To dissect the phenotypic and functional heterogeneity of STMs using single-cell transcriptomics and associated functional assays.

Methods: The relative proportions of the two major populations of STMs were quantified in 64 RA synovial biopsies (including 26 from RA patients in sustained remission), and in 8 healthy synovial tissues by flow cytometry. To uncover STM phenotypes, single-cell RNA sequencing of STMs from healthy donors $(n=4)$, active RA ( $n=7$; DAS28 $\geq 5.1$ ) and RA in remission ( $n=4$; DAS28 $\leq 2.6)$ was per formed with 10X Genomics. 21,000 STMs were sequenced and analysed (Seurat). For functional analysis, CD206/MerTK ${ }^{\text {neg }}$ and CD206/MerTK ${ }^{\text {pos }}$ STMs were sorted from biopsies of active RA $(n=15)$ and RA in remission $(n=8)$. These were stimulated in vitro with LPS (to mimic activation by joint damage) or with LPS plus the MerTK agonist GAS6 to activate MerTK ${ }^{\text {pos }}$ STMs; or co-cultured with FLS.

Results: The synovium of healthy subjects and RA patients in remission contain predominantly CD206/MerTK ${ }^{\text {pos }}$ STMs, whereas RA patients with any disease activity additionally contain substantial proportions of CD206/MerTK ${ }^{\text {neg }}$ STMs. In active RA, the CD206/MerTKneg STMs produce TNF while CD206/MerTK ${ }^{\text {pos }}$ STMs produce type I interferon following TLR4 activation. Interestingly, CD206/ MerTK ${ }^{\text {pos }}$ STMs from RA patients in remission showed a limited response to TLR stimulation, and their cytokine production was further inhibited by GAS6. This regulatory function of GAS6/MerTK was confirmed in macrophage-fibroblast co-culture assays: inhibition of MerTK in macrophages increased macrophage-induced cytokine production by FLS. STM single-cell transcriptomic analysis uncovered further STM heterogeneity in healthy, active RA and RA in remission (5 distinct subpopulations). These included three subpopulations that were not present in healthy and remission RA. These inflammatory subpopulations differ in their expression of surface receptors, spectrum of activated pathways and in their frequency in the synovium of patients with similar high DAS28. One of the subpopulations, characterised by increase metabolism, pro-inflammatory cytokines (e.g IL-1 $\beta$, BAFF) and chemokines, dominated in 3 out of 7 RA patients with active RA analysed; the second, characterised by high levels of MHC II and GPR receptors in 2 out of 7 patients while the third one characterised by high levels of alarmins (e.g. S100A8, 9 and 12) dominated in the remaining 2 inflamed RA synovia.

Conclusion: Pathogenic diversity of inflammatory synovial tissue macrophage subpopulations may partially account for unpredictable clinical responses in RA Identifying and targeting the predominant STM subpopulation may facilitate novel therapeutic development and eventually patient stratification.

Acknowledgement: Versus Arthritis RACE20298

Disclosure of Interests: Samuel Finlay : None declared, Lucy MacDonald : None declared, Barbara Tolusso: None declared, Aziza Elmesmari: None 
declared, Maria Rita Gigante: None declared, Clara Di Mario: None declared, Luca Petricca: None declared, Andrew Filer: None declared, Neal L Millar: None declared, Elisa Gremese Consultant for: AbbVie, BMS, Celgene, Janssen, Lilly, MSD, Novartis, Sanofi, UCB, Roche, and Pfizer, Speakers bureau: BMS, Speakers bureau: Roche, Speakers bureau: AbbVie, BMS, Celgene, Janssen, Lilly, MSD, Novartis, Sanofi, UCB, Roche, and Pfizer, lain Mclnnes Grant/research support from: AstraZeneca, Celgene, Compugen, Novartis, Roche, UCB Pharma Consultant for: AbbVie, Celgene, Galvani, Lilly, Novartis, Pfizer, UCB Pharma Thomas Otto: None declared, Stefano Alivernini Speakers bureau: BMS, Mariola Kurowska-Stolarska: None declared

DOI: 10.1136/annrheumdis-2019-eular.7631

\section{OP0221 OLIGOMERIC S100A4 INDUCES MONOCYTE INNATE IMMUNE MEMORY}

Emmanuel Karouzakis ${ }^{1}$, Agnieszka Pajak ${ }^{1}$, Niels Riksen², Leo Joosten², Mihai Netea $^{2}$, Esther Lutgens ${ }^{3}$, Eric Stroes ${ }^{3}$, Adrian Ciurea ${ }^{1}$, Oliver Distler ${ }^{1}$, Mariam Grigorian ${ }^{4}$, Michel Neidhart ${ }^{1} .{ }^{1}$ University Hospital Zurich, Zurich, Switzerland; ${ }^{2}$ Radboud University Medical Center, Nijmegen, Netherlands ${ }^{3}$ Academic Medical Center, Amsterdam, Netherlands; ${ }^{4}$ University of Copenhagen, Copenhagen, Denmark

Background: Trained immunity is a process of innate immune memory in which a primary stimulus such as beta-glucan can enhance the response of monocytes to secondary stimuli. The concept that specific damage associated molecular patterns (DAMPs) in rheumatoid arthritis (RA) could cause trained immunity which is involved in the disease pathogenesis has not been investigated so far. The oligomeric form of S100A4 (oS100A4) is a potent inducer of proinflammatory cytokines which is found in the plasma of patients with rheumatoid arthritis (RA).

Objectives: Aims are to investigate whether oS100A4 induces trained immunity in monocytes and characterize the molecular pathways involved in this process.

Methods: Monocytes were isolated from peripheral blood of healthy donors using anti-CD14 magnetic beads. To induce training, monocytes were stimulated with 2 $\mu \mathrm{g} / \mathrm{ml}$ of oS $100 \mathrm{~A} 4$ and $1 \mu \mathrm{g} / \mathrm{ml} \beta$-glucan for 24 hours $(n=8)$. We searched for differential gene expression by RNA sequencing in order to identify factors that play a role in the initial stages of trained immunity. On day 4 , LPS $(10 \mathrm{ng} / \mathrm{ml})$ was added. After 24 hours, IL-6 and TNFalpha were measured in cell culture supernatants by ELISA. The training protocol was repeated in monocytes transfected with PRDM8 siRNA using Lipofectamine $(n=4)$. In addition, plasma levels of S100A4, CCL5 and IL- 6 were measured in a cohort of RA patients $(n=36)$ and healthy controls $(n=18)$ by ELISA and PRDM8 transcripts in RA peripheral blood monocytes were quantified by RT-PCR.

Results: Monocytes primed with oS100A4 showed increased releases of IL-6 and TNFalpha in response to a subsequent LPS stimulation. RNA-Seq revealed the differential expression of 902 genes upon oS100A4 and 667 upon beta-glucan (mean and median $>2$ fold, $p<0.01$ ). Among the differential genes, 601 were upregulated in S100A4 and 447 in beta-glucan stimulated cells. Upregulated genes included chemokine/cytokine and epigenetic factors. When we compared the upregulated genes from oS100A4 and beta-glucan stimulated cells, $83 \%$ of chemokines/cytokines and $50 \%$ epigenetic factors were identical. Interestingly, the histone methyltransferase PRDM8 was found to be a major regulator of proinflammatory mediators by both stimuli. siRNA knockdown of PRDM8 abolished the training effect of oS100A4 by decreasing the LPS induced release of IL- 6 and TNFalpha $(p<0.01)$. Furthermore, we analyzed a cohort of monocytes taken from RA patients. Higher PRDM8 transcription in RA monocytes was associated with increased plasma levels of CCL5 and IL-6 ( $r=0.52$ and $0.55, p<0.01$ ). RA patients in remission versus active patients showed significantly lower PRDM8 transcripts $(p<0.05)$.

Conclusion: Oligomeric S100A4 induced trained immunity in monocytes similarly to beta-glucan. PRDM8 histone methyltransferase is involved in this process that appears to be activated in monocytes of RA patients.

Disclosure of Interests: Emmanuel Karouzakis: None declared, Agnieszka Pajak: None declared, Niels Riksen: None declared, Leo Joosten: None declared, Mihai Netea: None declared, Esther Lutgens: None declared, Eric Stroes: None declared, Adrian Ciurea Consultant for: AbbVie, Celgene, Janssen-Cilag, MSD, Eli Lilly, Novartis, Pfizer, UCB, Speakers bureau: Abbvie, Celgene, JanssenCilag, MSD, Eli Lilly, Novartis, Pfizer, UCB, Oliver Distler Grant/research support from: Prof. Distler received research funding from Actelion, Bayer, Boehringer Ingelheim and Mitsubishi Tanabe to investigate potential treatments of scleroderma and its complications, Consultant for: Prof. Distler has/had consultancy relationship within the last 3 years with Actelion, AnaMar, Bayer, Boehringer Ingelheim, ChemomAb, espeRare foundation, Genentech/Roche, GSK, Inventiva, Italfarmaco, iQvia, Lilly, medac, Medlmmune, Mitsubishi Tanabe Pharma,
Pharmacyclics, Novartis, Pfizer, Sanofi, Serodapharm and UCB in the area of potential treatments of scleroderma and its complications. In addition, he had/has consultancy relationship within the last 3 years with A. Menarini, Amgen, Abbvie GSK, Mepha, MSD, Pfizer and UCB in the field of arthritides and related disorders, Mariam Grigorian: None declared, Michel Neidhart: None declared DOI: 10.1136/annrheumdis-2019-eular.5675

FRIDAY, 14 JUNE 2019

\section{Seeing is believing: nanotechnologies in tissue imaging}

\begin{tabular}{|l|l}
\hline OP0222 & STUDY OF VERTEBRAL FRACTURE PREVALENCE \\
AND SCANOGRAPHIC BONE ATTENUATION \\
COEFFICIENT (SBAC-L1) IN PATIENTS WITH \\
RHEUMATOID ARTHRITIS AND ANKYLOSING \\
SPONDYLITIS VS. CONTROLS
\end{tabular}

Marine Fauny ${ }^{1 *}$, Eliane Albuisson ${ }^{2}$, Elodie Bauer ${ }^{1}$, Julia Perrier Cornet ${ }^{1}$, Isabelle Chary Valckenaere ${ }^{1}$, Damien Loeuille ${ }^{1}{ }^{1}$ CHRU Nancy, Rheumatology, Vandoeuvre les Nancy, France; ${ }^{2} \mathrm{CHRU}$ Nancy, Vandoeuvre les Nancy, France

Background: Osteoporosis is a common disease whose prognosis can be seriously impacted by the development of fractures that lead to functional limitations and may even have life-threatening sequelae. This disease is often underscreened, especially in at-risk populations that require multidisciplinary care such as patients with rheumatoid arthritis (RA) and ankylosing spondylitis (AS) $[1,2,3,4,5,6]$. Moreover, a recent study showed that the scanographic bone attenuation coefficient of the first lumbar vertebra (SBAC-L1) with a threshold at 145 Hounsfield Units (HU) identified $96.6 \%$ of patients in the general population with a vertebral fracture (VF), whereas DEXA (with a T-score $\leq-2,5$ ) identified only $39 \%$ of these patients [7].

Objectives: The aim of the study was to identify the prevalence of vertebral fractures (VFs) and to measure the scanographic bone attenuation coefficient of the first lumbar vertebra (SBAC-L1) based on CT-scan examinations of patients with rheumatoid arthritis (RA), patients with ankylosing spondylitis (AS) and in a control group.

Methods: This monocentric and retrospective study included patients who were evaluated between 2009 and 2017 with a diagnosis of RA based on the ACR/ EULAR criteria, those with a diagnosis of AS based on the New-York criteria, and a RA-matched control group. All of the patients received a CT-scan. The osteoporosis risk factors, data from dual energy X-ray absorptiometry (DEXA) and clinical characteristics were collected. VFs were determined via CT-scans according to the Genant classification, and the SBAC-L1 was measured in Hounsfield units (HU). SBAC-L1 $\leq 145 \mathrm{HU}$ (fracture threshold) defined patients at risk of VFs.

Results: A total of 244 patients were included (105 RA, 83 AS, 56 controls). The AS group was younger and primarily consisted of males. Of the 4,365 vertebrae studied, 66 osteoporotic VFs were found in 36 patients: 18 (17.1\%) patients with RA, $13(15.7 \%)$ patients with AS and $5(8.9 \%)$ controls. The SBAC-L1 was 142.2 $( \pm 48.4) \mathrm{HU}$ for the RA group and $142.8( \pm 48.2)$ for the AS group, both of which were significantly lower than that of the control group $(161.8( \pm 42.7) \mathrm{HU})$. Of the 36 patients with VFs and rheumatism, $28 \%$ had a T-score $\leq-2.5 \mathrm{SD}$, and $71.4 \%$ had a SBAC-L1 $\leq 145 \mathrm{HU}$. A T-score $\leq-2.5 \mathrm{SD}$ and a SBAC-L1 $\leq 145 \mathrm{HU}$ were associated with the presence of a VF $(\mathrm{OR}=2.35[\mathrm{C} 195 \%: 1.12-4.92]$ and 2.06 [CI95\%: 1.04-4.10]), respectively.

Conclusion: The SBAC-L1 was significantly lower in the RA and AS groups than in the control group. Furthermore, SBAC-L1 $\leq 145 \mathrm{HU}$ was associated with a higher risk of VFs, with an odds ratio similar to that of a DEXA.

\section{REFERENCES:}

[1] Toledano E. Reumatol Clin. 2012 Nov-Dec;8(6):334-41.

[2] Dougado M. Ann Rheum Dis. 2014;73:62-8.

[3] McKeown E. Rheumatol Oxf Engl. 2012;51:1662-9.

[4] Van der Weijden MA. Clin Rheumatol. 2012 Nov;31(11):1529-35.

[5] Ghozlani I. Bone. 2009 May;44(5):772-6.

[6] Ardizzone M. Rev Med Interne. 2006 May;27(5):392-9.

[7] Pickhardt PJ. Ann Intern Med. 2013;158(8):588-95.

Disclosure of Interests: None declared DOI: 10.1136/annrheumdis-2019-eular.305 